\title{
XAFS Study of Defect Structure in Ionic Crystals
}

\author{
T. Murata \\ Department of Physics, Kyoto University of Education, Fukakusa, Fushimi, Kyoto 612, Japan
}

\begin{abstract}
Local lattice structures around the defects in alkali halides and Ila-VIb compounds such as solid solutions and impurities are presented and discussed. The possibility of the direct observation of the relaxed excited states of with the use of high brilliance third generation SR light is also discussed.
\end{abstract}

\section{INTRODUCTION}

Defects in ionic crystals play various important roles in many aspects, such as formation of color centers by negative ion vacancies in alkali halides [1], luminescence centers by heavy impurity ions in many crystals [2], centers of intrinsic luminescence in alkali halides [3]. These characteristics are strongly related to the local lattice structure around the specific defects. Many research works on the electronic structure of the solids have been done mainly through optical measurements or electron spin resonance. These measurements give only indirect information of the local lattice structure. In most of the above studies, the lattice relaxation around the defects is supposed to occur whilst maintaining the lattice structure of the host crystal. In $\mathrm{x}$-ray absorption study, however, it is already well known that the local structure of the substituted guest atoms/ions in solid solutions does not follow the Vegard's law, but rather is similar to the compound of the guest with the counterpart of the substituted atom/ion of the host [4]. To date, this effect has not been included in the physics of the defect in ionic crystals.

Generally, defects or imperfections in solids can be classified according to several types; a) point defects of the lattice, b) interstitial or substituted guest ions/atoms, c) solid solutions of two compounds usually with one common component ion/atom, d) formation of dimers or trimers of the component ions in the excited state. The example of case a) is the $F$ center in alkali halides. This is attributed to a trapped electron in a negative ion vacancy of the crystal. The observation of the local structure of the defect of this type by XAFS technique is difficult because the number of defects is too small (about $10^{18} / \mathrm{cm}^{3}$ ) to produce the observable signal in the $x$-ray absorption spectrum. Case $b$ ) is the most common, and is related to the luminescent properties of solids, observable by fluorescence XAFS technique. Solid solutions (case c) are often used for the artificial changing of the lattice parameter of the crystal. In the case of alkali halides, potassium and rubidium halides and alkali chlorides and bromides mix together well to form stable solid solution over the whole concentration range of the two salts due to the small differences in ionic radii of the constituent elements. In some cases, other ions having a large difference in ionic sizes are introduced to explore the extreme case of the lattice deformation. This is the ideal case for the XAFS observation. XAFS measurements on the solid solution systems have been extensively made so far [5-8]. Case d) occurs only in the excited states. The most well known effect is the self-trapped exciton in alkali halides. When an electron is excited by the photon from the halide ion, another neighboring halide ion is attracted by the Coulomb force, and forms a $\mathrm{V}_{\mathrm{K}}$ center, which is a (halogen) ${ }_{2}^{-}$ dimer along the $(110)$ direction in the lattice. The $\mathrm{V}_{\mathrm{K}}$ center is effectively a hole trapped by (halogen) ${ }_{2}{ }^{2-}$ molecular ion. The excited electron is then trapped by the $V_{K}$ center. The $\left(V_{K}+e\right)$ state is calied the relaxed excited state of the intrinsic luminescence of alkali halides. The nature of intrinsic luminescence is discussed in detail in the textbook [3]. The XAFS measurement of this system should be made for excited states, which requires a special technique of synchronous measurement of the X-ray absorption with laser excitation.

In this paper, the results of several cases of local structure around the defects of solid solutions and impurities are presented. For the solid solutions, two systems with $\mathrm{KCl}$ were chosen; $\mathrm{KCl}_{1-x} \mathrm{Br}_{\mathrm{x}}$ for the halogen substitution, and $\mathrm{K}_{1-x} \mathrm{Rb}_{\mathrm{x}} \mathrm{Cl}$ for the alkali substitution. The measurements were done fairly long time ago, and a part of the results of the former system has been already reported earlier by the author [9]. However, all the analysis were repeated using a new analysis program to compare the results of the Rb-substituted system. For the impurity system, IIa-VIb compounds activated with foreign metal ions were measured. These are known as materials of cathodoluminescence and electroluminescence. Samples chosen are powdered $\mathrm{CaS}: \mathrm{Pb}^{2+}$ and $\mathrm{SrS}: \mathrm{Mn}^{2+}$. Both of the host materials crystallize in the $\mathrm{NaCl}$ structure. The former is the case of a heavy impurity ion in the bulk with light cation, and the latter is the opposite case. Finally, the possibility of the observation of relaxed excited states with the use of high brilliance third generation synchrotron radiation light is discussed briefly.

\section{EXPERIMENTAL}

All the experiments were performed in the Photon Factory. Absorption measurements of $\mathrm{Br} \mathrm{K}$ - and $\mathrm{Rb}$ K-edges for solid solutions were done in 1982-1984 at the BL-10B with electron beam energy of $2.5 \mathrm{GeV}$ and a maximum stored current of $100 \mathrm{~mA}$. Data were collected with Si (311) channel-cut monochromator. Harmonic rejection was not made. Ion chambers with flowing $\mathrm{N}_{2}$ gas and Ar gas were used for detecting the incident and transmitted X-rays, respectively. Energy resolution was estimated to be about $0.5 \mathrm{eV}$ by the $\mathrm{Cu}$ XAFS spectrum. Fluorescence and absorption measurements for impurity systems of $\mathrm{IIa}-\mathrm{VTb}$ compounds were done at BL-7C station [10]with positron beam energy of $2.5 \mathrm{GeV}$ and a ring current of $350-250 \mathrm{~mA}$. 
$\mathrm{Si}(111)$ monochromator with a fixed exit slit was used for the measurements. Higher harmonics were rejected either by using a pair of the fused quartz mirrors at a grazing incidence for $\mathrm{Ca}$ and $\mathrm{Mn}$ edges or by detuning the first crystal of the monochromator to about $60 \%$ for other edges. Fluorescence measurements for $\mathrm{Pb} \mathrm{L}_{3}$ and $\mathrm{Mn} \mathrm{K}$ edge were made with using a Lytle fluorescence detector [11]. Absorption measurements were also done for the cations of the host materials of CaS and SrS and the sulfides of impurity cations, i.e., $\mathrm{PbS}$ and $\mathrm{MnS}$. Samples were cooled with a cryostat, down to $80 \mathrm{~K}$ for solid solutions, and to $20 \mathrm{~K}$ for the impurity systems.

Samples of solid solutions of $\mathrm{KCl}+\mathrm{KBr}$ and $\mathrm{KCl}+\mathrm{RbCl}$ were prepared by melting the known fractions of two pure materials in a platinum crucible, and subsequently quenching it down to room temperature. The ingot was ground to fine powder, and heaped loosely on a membrane filter [12]. The thicknesses of the samples were determined to have edge jumps $\Delta \mu t$ of 0.5 to 1.0 and with a total absorption $\mu \mathrm{t}$ less than 2.5 .

Data reduction process of the XAFS spectra is the standard one. After removing the pre-edge contribution by Victoreen formula added by a constant term, the atomic background absorption was determined by the method proposed by Cook and Sayers [13]. The location of the origin of the wavenumber was determined by the peak of the first derivative of the absorption spectrum at the edge. The wavenumber $(k)$ range of the Hanning window functions put onto all the normalized $\chi(k)$ XAFS spectra before the Fast Fourier Transform (FFT) was set exactly the same (from 2.0 to $10.5 \AA^{-1}$ ) with the flat part covering $80 \%$ of the range. To follow the recommendation in the Standard and Criteria Workshop Reports [14], the $\chi(k)$ data were multiplied with a $k$ grid spacing, $1 / 16$, and divided by $\sqrt{ } \pi$ before calculating the FFT. The R-space fitting calculations of the first shell were made using the EXAFIT program developed by Bauchspiess [15]. Amplitude and phase functions containing the electron mean free path were obtained from FEFF (Ver. 6.01) program [16].

\section{RESULTS AND DISCUSSION}

\section{1 $\mathrm{KCl}_{1-\mathrm{x}} \mathrm{Br}_{\mathrm{x}}$ and $\mathrm{K}_{1-\mathrm{x}} \mathbf{R b}_{\mathrm{x}} \mathrm{Cl}$ Solid Solution Systems}

Figures 1 and 2 show the XAFS $\chi(\mathrm{k})$ of $\mathrm{Br} \mathrm{K}$-edge in $\mathrm{KCl}_{1-\mathrm{x}} \mathrm{Br}$ and $\mathrm{Rb} \mathrm{K}$-edge in $\mathrm{K}_{1-\mathrm{x}} \mathrm{Rb}_{\mathrm{x}} \mathrm{Cl}$ systems. The magnitudes of the Fourier transforms of $\mathrm{k}^{3}$ weighted $\chi(\mathrm{k})$ are shown in Figs. 3 and 4 . The positions of the first peak of the Fourier spectra changes only very slightly for both systems. Apparent increases of the heights of the peaks are observed in the lower concentration range for both systems. Fitting calculations for the first shell of all the spectra were made with the EXAFTT program. Results for $\mathrm{KCl}_{0.96} \mathrm{Br}_{0.04}$ and $\mathrm{K}_{0.96} \mathrm{Rb}_{0.04} \mathrm{Cl}$ are shown in Figures 5 and 6 . The vertical lines in the figures indicate the range of fitting. In the process of fitting, the first coordination number was fixed at 6 to avoid the correlation between the coordination numbers and Debye-Waller factors. Figures 7 and 8 show the change in the distance between $\mathrm{Br}-\mathrm{K}$ and $\mathrm{Rb}-\mathrm{Cl}$ respectively against the change in concentration. Numerical results are given in Tables $I$ and II. It should be noted that the Debye-Waller factor for $\mathrm{KCl}_{0.96} \mathrm{Br}_{0.04}$ sample is extremely small, which corresponds to the large peak height of the Fourier spectrum. This means that the deformation around the guest $\mathrm{Br}$ ions in the $\mathrm{KCl}$ matrix is smaller than in the case of pure $\mathrm{KBr}$. A similar tendency is observed for $\mathrm{Rb}$-substituted case. This can be reasonably understood in the following way. The $\mathrm{Br}^{-}$and $\mathrm{Rb}^{+}$ions are both larger than the ions of matrix, $\mathrm{Cl}^{-}$and $\mathrm{K}^{+}$. Therefore, the lattice relaxation around the guest ions induces an expansion of the host lattice. This causes a strong internal stress on the guest ions, and results in the smaller deviation of the first shell distance.

In contrast to the rather simple change in the first shell of the Fourier spectra, higher shell spectra show more complicated behavior. The peaks of the second shell which are clearly seen in pure $\mathrm{KBr}$ and $\mathrm{RbCl}$ spectra decrease rapidly with decreasing concentration of $\mathrm{Br}^{-}$or $\mathrm{Rb}^{+}$ions in $\mathrm{KCl}$ matrix. Conversely, as shown in Figures 3 and 4, gradual evolution of the peaks of the higher shell is observed. In order to analyze these structures, the calculations with FEFF6 program were performed for samples of $4 \%$ of guest ions in the $\mathrm{KCl}$ matrix. The distances of the first coordination were taken from the results of the fit, and higher shell distances were taken from the values of $\mathrm{KCl}$ matrix in the calculations. The Debye-Waller factors used were also taken from the fitting results. The parameters RMAX and NLEG in the FEFF6 were set to $8 \AA$ and 8 respectively for both cases. The results are given in Figures 9 and 10. All the peaks are well reproduced by the calculation especially for $\mathrm{KCl}_{0.96} \mathrm{Br}_{0.04}$. For $\mathrm{Rb}$ ions in $\mathrm{KCl}$ matrix the fit is poorer than the case of $\mathrm{Br}$ ions, but the global structure is fairly well reproduced by the simulation. The gradual evolution of the peak and its shift in the Fourier spectra with decreasing concentration of the composition $x$ can be understood as the average structural change of the $\mathrm{KCl}$ matrix. As shown in Figures 7 and 8 , the difference between the distance observed by XAFS and that by diffraction gradually increases. The shift of the higher shell peaks in the Fourier spectra reflects the above character. The results show that the structure of the matrix can be observed from the impurity ions. Malzfeldt et al. [17] reported the XAFS results for $\mathrm{Kr}$ and Ar alloys, and analyzed the Ar matrix structure viewed from $\mathrm{Kr}$ impurity atom. The present cases are ternary alloys, and are more complicated than the binary alloy. Nevertheless, the structure of the host $\mathrm{KCl}$ matrix could be observed up to the distance of $8 \AA$ from the central absorbing ion. This opens a new possibility of the application of the XAFS technique for the analysis of the host matrix viewed from the embedded impurities.

\section{2 $\mathrm{CaS} \mathrm{Pb}^{2+}$ and $\mathrm{SrS}: \mathrm{Mn}^{2+}$}

In Figures 11 and 12 are shown the $\chi(\mathrm{k})$ spectra and their Fourier transforms for $\mathrm{CaS}: \mathrm{Pb}$ and its reference $\mathrm{PbS}$, and $\mathrm{SrS}: \mathrm{Mn}$ and its reference $\mathrm{MnS}$, respectively. The positions of the first peak of Fourier spectra of $\mathrm{CaS}: \mathrm{Pb}$ and $\mathrm{PbS}$ are almost identical to each other. The fitting analysis was also performed for the first shell, and the results are shown in Fig. 13, with 
the derived parameter listed in Table III. The discrepancy of the fit in the low $\mathrm{R}$ region is due to the remaining low-frequency component of the Fourier spectrum. The Debye-Waller factor of the CaS: $\mathrm{Pb}$ is small compared with that of $\mathrm{PbS}$. This can be understood in the same way as in the case of solid solutions of alkali halides. The Ca-S distance of the host CaS is $2.852 \AA$ and is smaller than that of $\mathrm{Pb}$ and $\mathrm{S}(2.954 \AA)$, which causes the expansion of the host lattice. The internal stress induced on the $\mathrm{Pb}$ impurity ions in the host as a reaction of the lattice expansion should be strong, and results in the small deviation of the first shell distance.

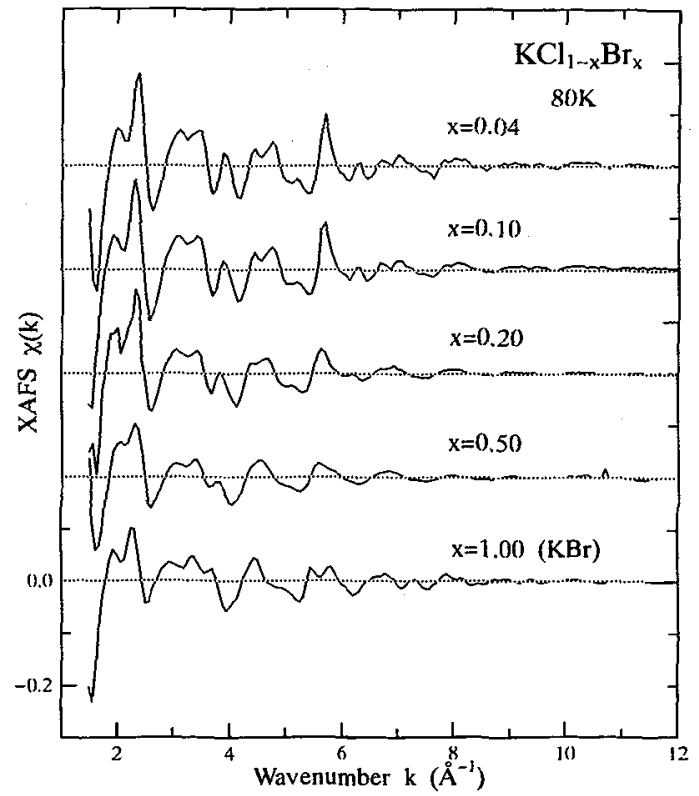

Figure 1: Br K-XAFS spectra of $\mathrm{KCl}_{1-\mathrm{x}} \mathrm{Br}_{\mathrm{x}}$ solid solution system Figure 2: $\mathrm{Rb} \mathrm{K}-\mathrm{XAFS}$ spectra of $\mathrm{K}_{1-\mathrm{x}} \mathrm{Rb}_{\mathrm{x}} \mathrm{Cl}$ solid solution system measured at $80 \mathrm{~K}$.

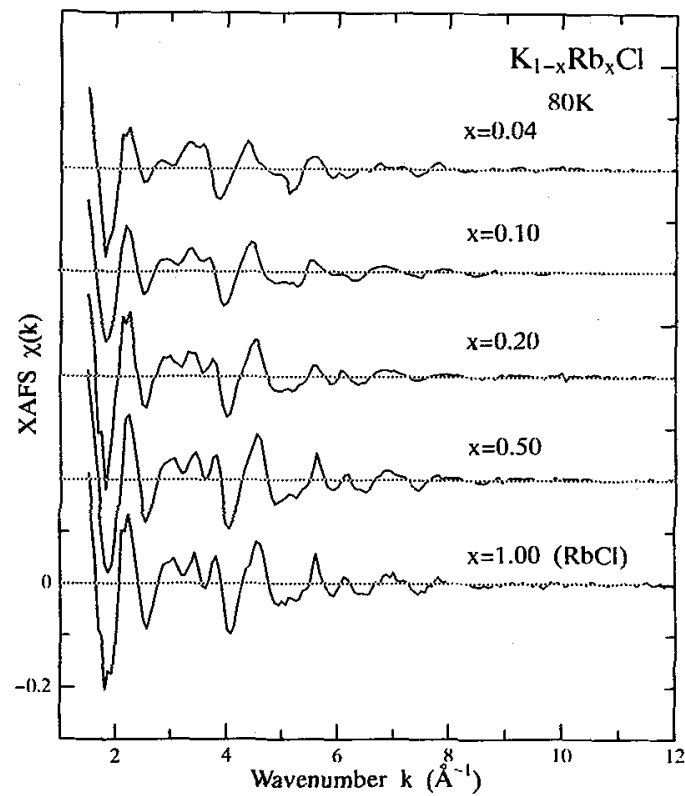

measured at $80 \mathrm{~K}$.

Table I: First shell distance $\mathrm{R}$ and Debye-Waller factor $\sigma^{2}$ of $\mathrm{Br}$ ion in $\mathrm{KCl}_{1 \times \mathrm{x}} \mathrm{Br}_{\mathrm{x}}$ solid solution system obtained from fitting calculation. Coordination number was fixed to 6 .

\begin{tabular}{ccc}
\hline Composition $x$ & $\mathrm{R}(\AA)$ & $\sigma^{2}\left(\times 10^{-2} \AA^{2}\right)$ \\
\hline $1.00(\mathrm{KBr})$ & $3.258 \pm 0.010$ & $0.808 \pm 0.045$ \\
0.80 & $3.247 \pm 0.008$ & $0.907 \pm 0.055$ \\
0.50 & $3.232 \pm 0.009$ & $0.903 \pm 0.055$ \\
0.35 & $3.207 \pm 0.008$ & $0.808 \pm 0.053$ \\
0.20 & $3.209 \pm 0.009$ & $0.860 \pm 0.055$ \\
0.15 & $3.212 \pm 0.008$ & $0.702 \pm 0.047$ \\
0.10 & $3.189 \pm 0.006$ & $0.633 \pm 0.043$ \\
0.04 & $3.208 \pm 0.006$ & $0.475 \pm 0.043$ \\
\hline
\end{tabular}

Table II: First sheil distance $\mathrm{R}$ and Debye-Waller factor $\sigma^{2}$ of $\mathrm{Rb}$ ion in $\mathrm{K}_{1-\mathrm{x}} \mathrm{R} \mathrm{b}_{\mathrm{x}} \mathrm{Cl}$ solid solution system obtained from fitting calculation. Coordination number was fixed to 6 .

\begin{tabular}{ccc}
\hline Composition $x$ & $R(\AA)$ & $\sigma^{2}\left(\times 10^{-2} \AA^{2}\right)$ \\
\hline $1.00(\mathrm{RbCl})$ & $3.266 \pm 0.010$ & $0.952 \pm 0.064$ \\
0.80 & $3.253 \pm 0.008$ & $1.108 \pm 0.053$ \\
0.50 & $3.249 \pm 0.010$ & $0.976 \pm 0.061$ \\
0.35 & $3.235 \pm 0.010$ & $0.741 \pm 0.056$ \\
0.20 & $3.215 \pm 0.010$ & $1.049 \pm 0.059$ \\
0.15 & $3.222 \pm 0.008$ & $0.684 \pm 0.046$ \\
0.10 & $3.217 \pm 0.008$ & $0.704 \pm 0.050$ \\
0.04 & $3.216 \pm 0.008$ & $0.769 \pm 0.055$ \\
\hline
\end{tabular}

Table III: First shell distance $\mathrm{R}$ and Debye-Waller factor $\sigma^{2}$ of $\mathrm{Pb}$ ions obtained from fitting calculation for $\mathrm{PbS}$ and $\mathrm{CaS}: \mathrm{Pb}$.

\begin{tabular}{ccc}
\hline Material & $\mathrm{R}(\AA)$ & $\sigma^{2}\left(\times 10^{-2} \AA^{2}\right)$ \\
\hline $\mathrm{PbS}$ & $2.95 \pm 0.01$ & $0.86 \pm 0.07$ \\
$\mathrm{CaS}: \mathrm{Pb}$ & $2.94 \pm 0.01$ & $0.49 \pm 0.04$ \\
\hline
\end{tabular}




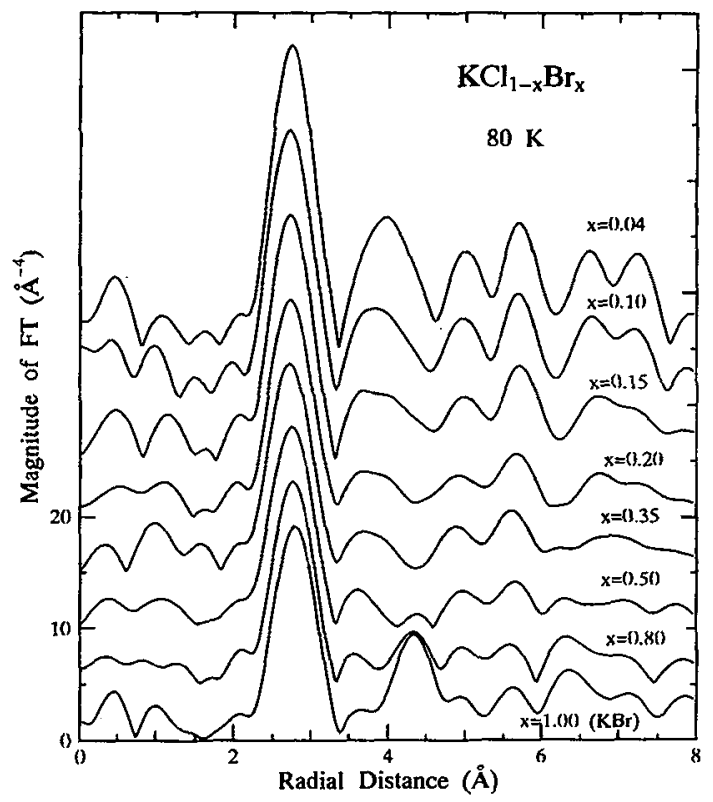

Figure 3: Magnitudes of Fourier transform of $\mathrm{k}^{3}$ weighted $\chi(\mathrm{k})$ or $\mathrm{Br} \mathrm{K}-\mathrm{XAFS}$ of $\mathrm{KCl}_{1-x} \mathrm{Br}_{\mathrm{x}}$ solid solution system measured at $80 \mathrm{~K}$.

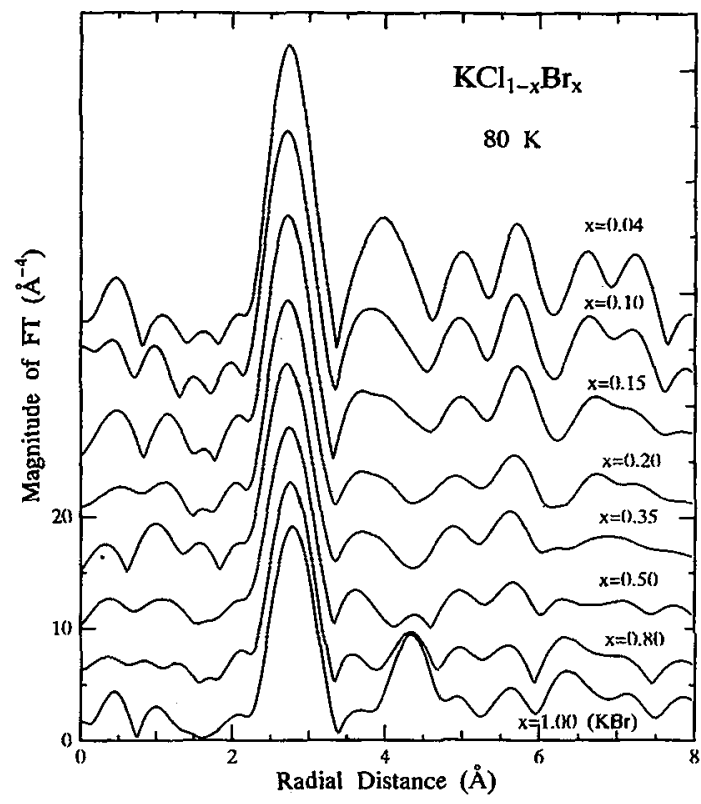

Figure 4: Magnitudes of Fourier transform of $\mathbf{k}^{3}$ weighted $\chi(\mathbf{k})$ of $\mathrm{Rb} \mathrm{K}$-XAFS of $\mathrm{K}_{1 \cdot \mathrm{x}} \mathrm{Rb}_{\mathrm{x}} \mathrm{Cl}$ solid solution system measured at $80 \mathrm{~K}$.

The result of SrS:Mn is more complicated as shown in Figure 12. Both $\chi(\mathrm{k})$ 's and Fourier spectra are very different. The first shell of the Fourier spectrum of SrS:Mn is very small in height and wide in width. We could not obtain a reasonable fit for this shell with a single shell fitting calculation. This suggests that the deformation around the Mn impurity ions in the host $\mathrm{SrS}$ may be very large due to the small size of the impurity $\mathrm{Mn}$ ion comparing to the host $\mathrm{Sr}$ ion. The distance of $\mathrm{Sr}$ and $S$ was observed to be $3.005 \AA$ which is much larger that the value of $\mathrm{MnS}(2.586 \AA)$. The $\mathrm{Mn}$ impurity ions have a large free space in the host lattice, and can be relaxed at off-center position. More detailed analysis is necessary to obtain a definite conclusion for this case.

The higher shell structures of both samples are very different from the hosts. As shown in Figure 11, the second peak of the $\mathrm{CaS}: \mathrm{Pb}$ is located at smaller $\mathrm{R}$ than that of the host $\mathrm{PbS}$ with a very large height. For $\mathrm{Mn}$ in $\mathrm{SrS}$, three large peaks are observed in the higher $\mathbf{R}$ region (Fig. 12). We performed the same calculation used in the analysis of the solid solutions to analyze the nature of the higher shell structure. By using the first shell distance of $\mathrm{Pb}$ and $\mathrm{S}$ or that of $\mathrm{Mn}$ and $\mathrm{S}$ and other lattice parameters of the host (CaS or SrS) for the higher shells, the FEFF calculations were performed. The results of the calculation are given in Figures 14 and 15. The fit is very good for $\mathrm{CaS}: \mathrm{Pb}$. The Fourier spectrum was well reproduced by the calculation, including the large second peak. This shows clearly that the structure of the host CaS matrix is observed from the impurity $\mathrm{Pb}$ ion. The result of $\mathrm{SrS}: \mathrm{Mn}$ is not good as in $\mathrm{CaS}: \mathrm{Pb}$. The first peak of the calculated spectrum corresponds to the $\mathrm{Mn}-\mathrm{S}$ coordination. The structures at higher $\mathbf{R}$ values are reasonably understood as the reflection of the SrS matrix structure. The peaks between 4 and $5 \AA$ of the experimental data are well reproduced. Therefore, it can be concluded that the structure of the host $\mathrm{SrS}$ is partly observed in this system.

\section{POSSIBILITY OF DIRECT OBSERVATION OF THE RELAXED EXCTTED STATES WITH XAFS}

The structure of the excited state of solids often differs from that of the ground state. As stated in the beginning of the paper, the structure of the relaxed excited state (RES) in alkali halides is well understood as the (halogen) ${ }_{2}^{-}$center with a trapped electron. The structure of the RES is classified into three types; on-center, off-center, and intermediate [3]. So far, however, the direct observation of the distance between the two halogen ions of the excited state and local structure around them have not been reported. The life time of the RES is the order of $10^{-6} \mathrm{~s}$. At present, even with a high speed data acquisition method such as the dispersive XAFS mode, it is impossible to observe the change. One of possibilities for observing this is to use a modulation technique[18,19] with a laser, which is a widely used in the investigation of the electronic structure in solids. The laser is operated synchronously with the synchrotron radiation for the absorption measurement. The excited states are produced by the laser light, and the absorption from the excited states can be selectively detected with the $\mathrm{X}$-rays. The signal obtained is a derivative of the normal absorption. Emura and Maeda [20] performed a model calculation for this measurement, and estimated the intensity of the derivative as about $10 \%$ of the normal $\chi(\mathrm{k})$. In order to measure such a small change in the 
signal, intense light and a stable experimental setup are necessary. This condition can be achieved only with the third generation synchrotron source.

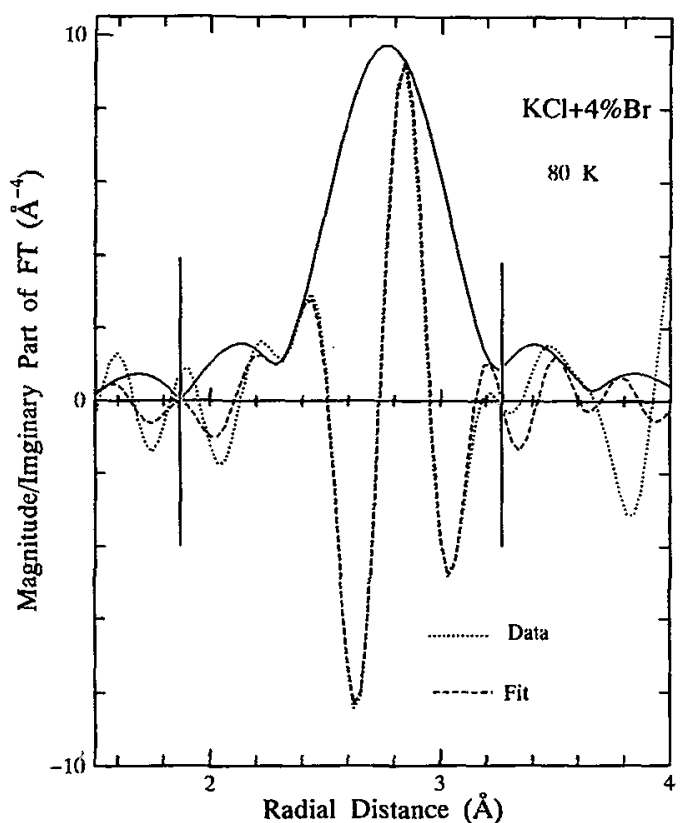

Figure 5: R-space fit of the first shell of $\mathrm{Br}$ in $\mathrm{KCl}_{0.96} \mathrm{Br}_{0.04}$ at $80 \mathrm{~K}$. The fitting calculation was made in the range shown by vertical lines in the figure.

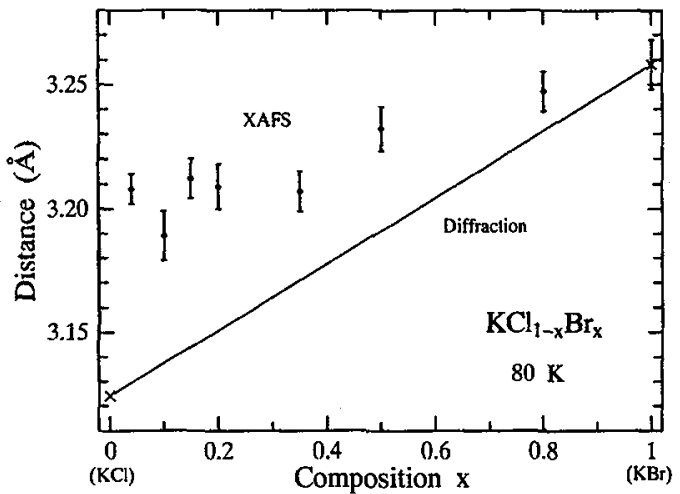

Figure 7: Change in lattice parameters in $\mathrm{KCl}_{1 . x} \mathrm{Br}_{x}$ at $80 \mathrm{~K}$ compared to those deduced from Br XAFS.

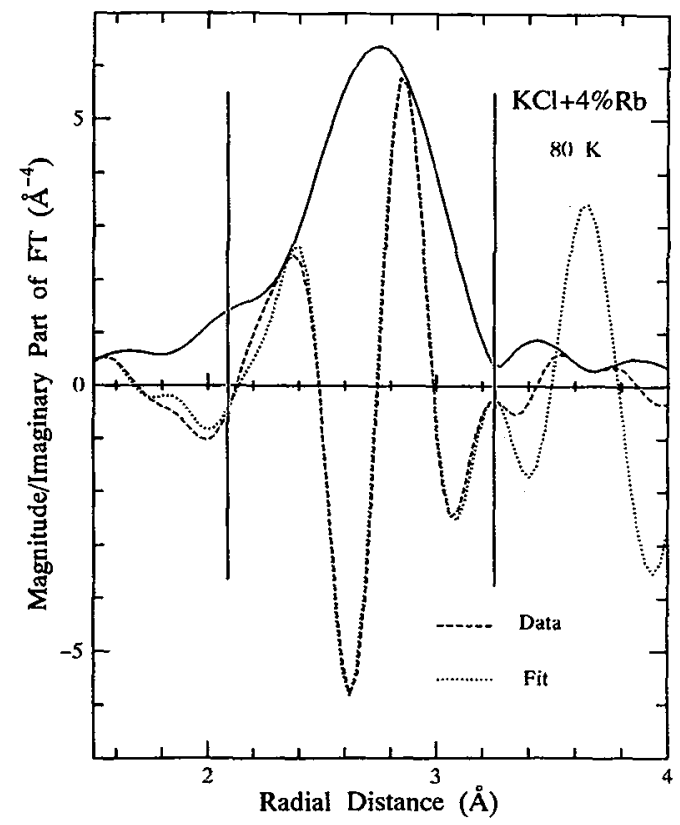

Figure 6: R-space fit of the first shell of $\mathrm{Rb}$ in $\mathrm{K}_{0.96} \mathrm{R} \mathrm{b}_{0.04} \mathrm{Cl}$ at $80 \mathrm{~K}$. The fitting calculation was made in the range shown by vertical lines in the figure.

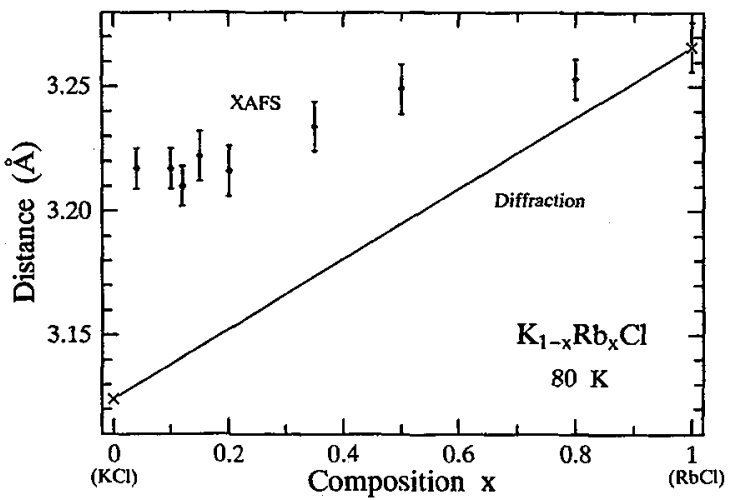

Figure 8: Change in lattice parameters in $\mathrm{K}_{1-\mathrm{x}} \mathrm{Rb} \mathrm{Cl}_{\mathrm{x}} \mathrm{Cl}$ at $80 \mathrm{~K}$ compared to those deduced from $\mathrm{Rb}$ XAFS.

\section{CONCLUSION}

The local structures of the solid solutions of alkali halides and impurities in $\mathrm{Ia}-\mathrm{VIb}$ compounds with $\mathrm{NaCl}$ structure were analyzed. It was commonly observed that the near neighbor distance of the guest ion in the matrix does not follow the Vegard's law. The Debye-Wailer factor is small at lower concentrations when the size of the guest ion is larger than the matrix ions. The analysis with FEFF program has revealed that the structure of the matrix viewed from the impurity can be seen in the higher shell structure of the Fourier spectra. 

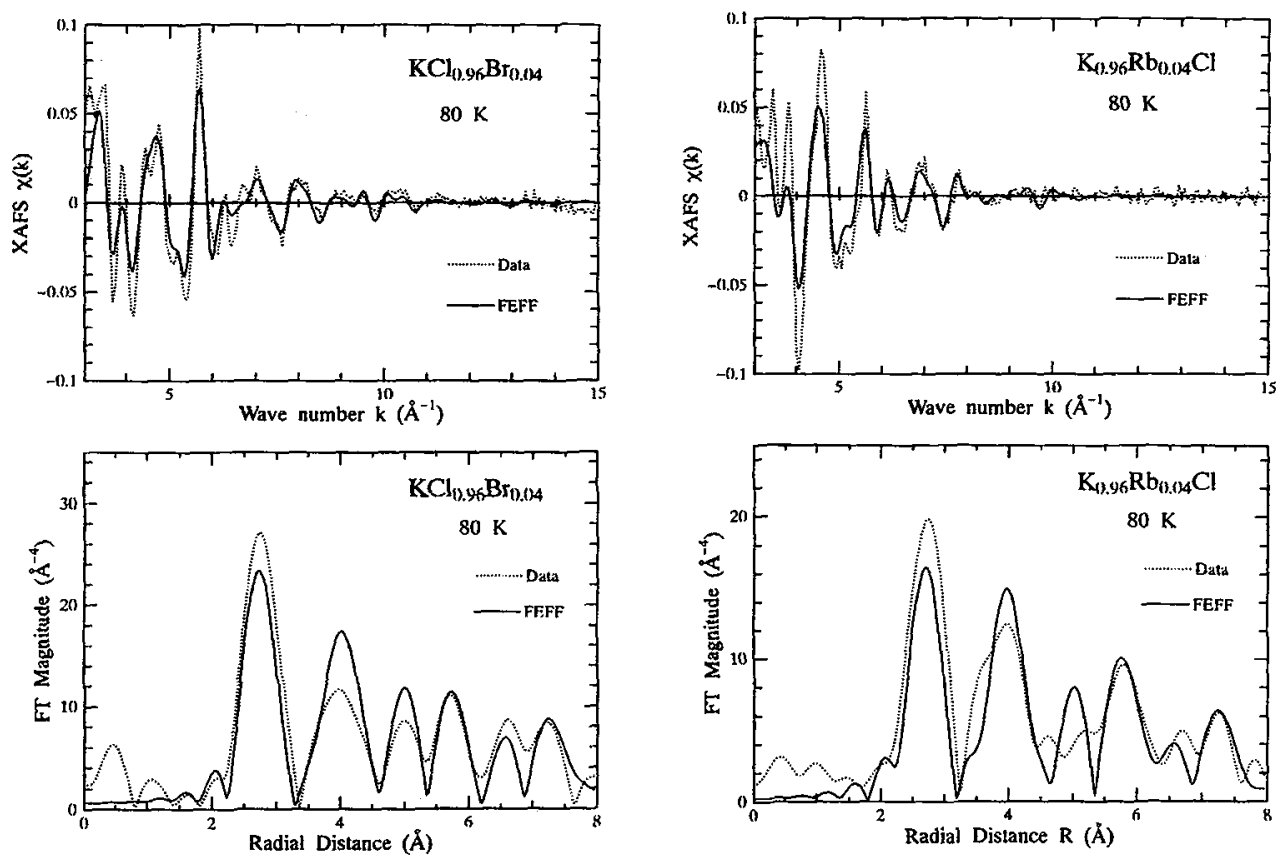

Figure 9: Comparison of the experimental and calculated spectra $\chi(k)$ 's and the Fourier transforms of $\mathbf{k}^{3}$-weighted $\chi(k)$

Figure 10: Comparison of the experimental and calculated spectra $\chi(\mathrm{k})$ 's and the Fourier transforms of $\mathrm{k}^{3}$-weighted $\chi(\mathrm{k})$ in $\mathrm{K}_{0.96} \mathrm{Rb}_{0.04} \mathrm{Cl}$.
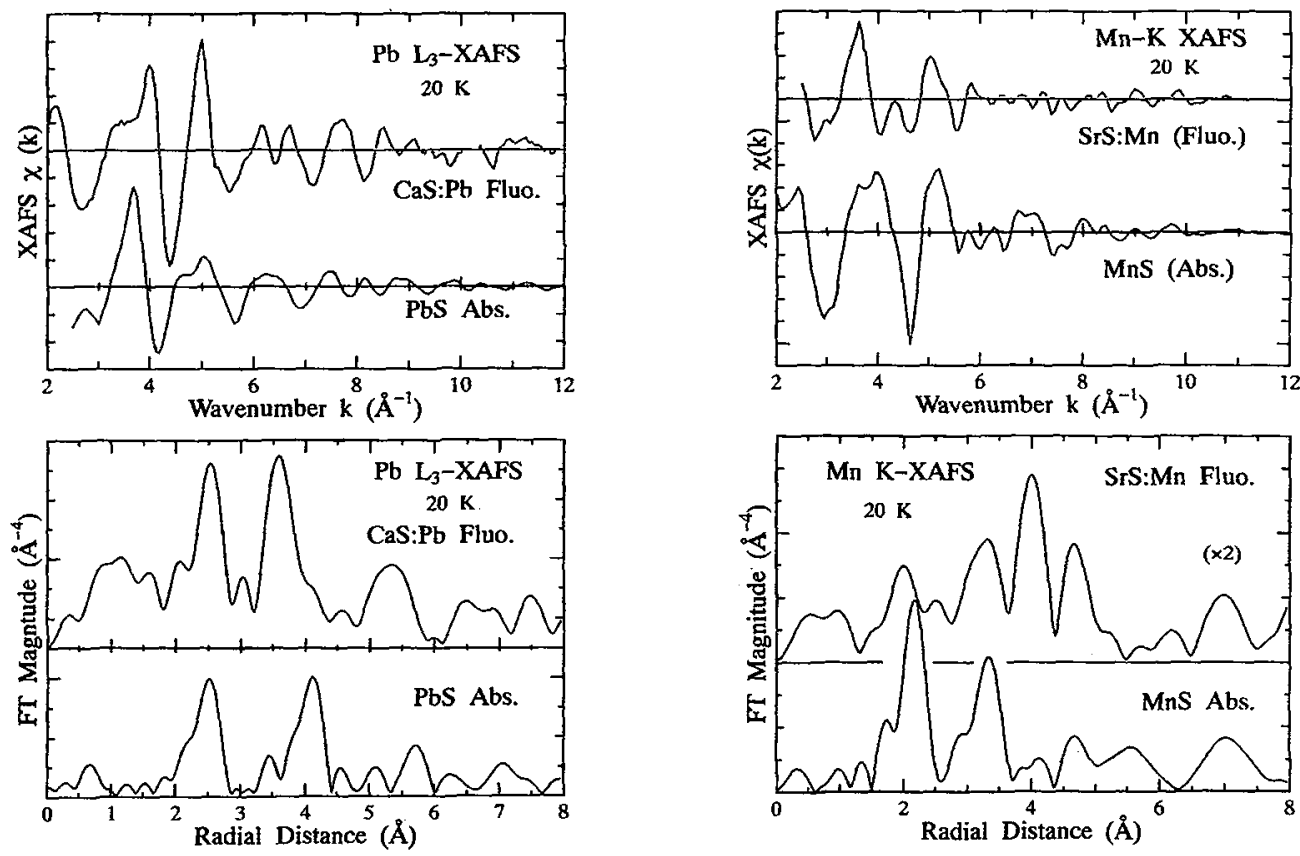

Figure 11: $\chi(\mathrm{k})$ and Fourier spectra of $\mathrm{k}^{3}$-weighted $\chi(\mathrm{k})$ of $\mathrm{Pb}$ XAFS of $\mathrm{PbS}$ and $\mathrm{CaS}: \mathrm{Pb}$ measured at $20 \mathrm{~K}$.

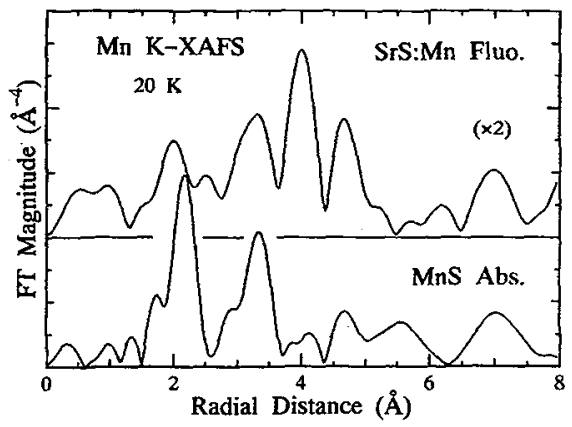

Figure 12: $\chi(k)$ and Fourier spectra of $\mathrm{k}^{3}$-weighted $\chi(\mathrm{k})$ of $\mathrm{L}_{3}$-edge Mn K-edge XAFS of MnS and SrS:Mn measured at $20 \mathrm{~K}$. 


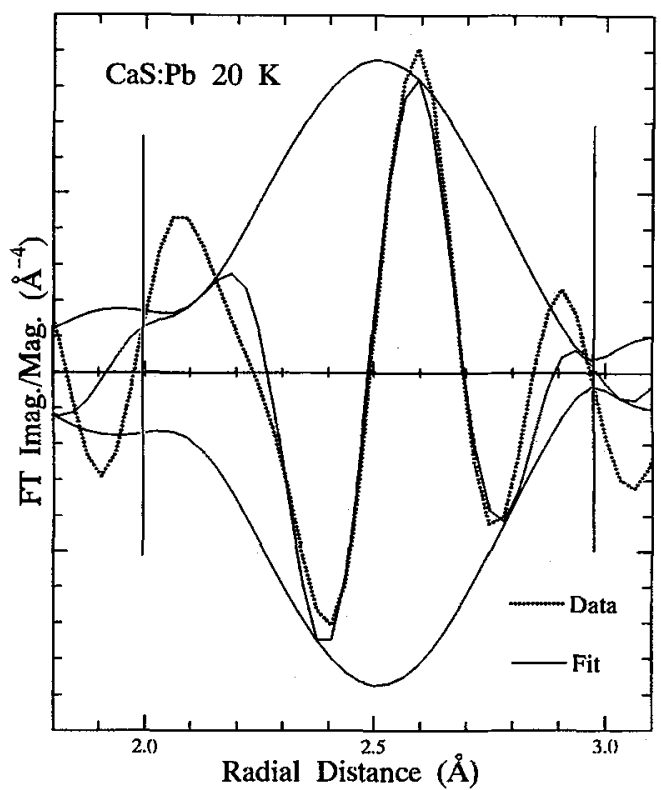

Figure 13: R-space fit of first shell of Fourier spectrum of $\mathrm{CaS}: \mathrm{Pb}$. 'The fitting calculation was made in the range shown by vertical lines in the figure.
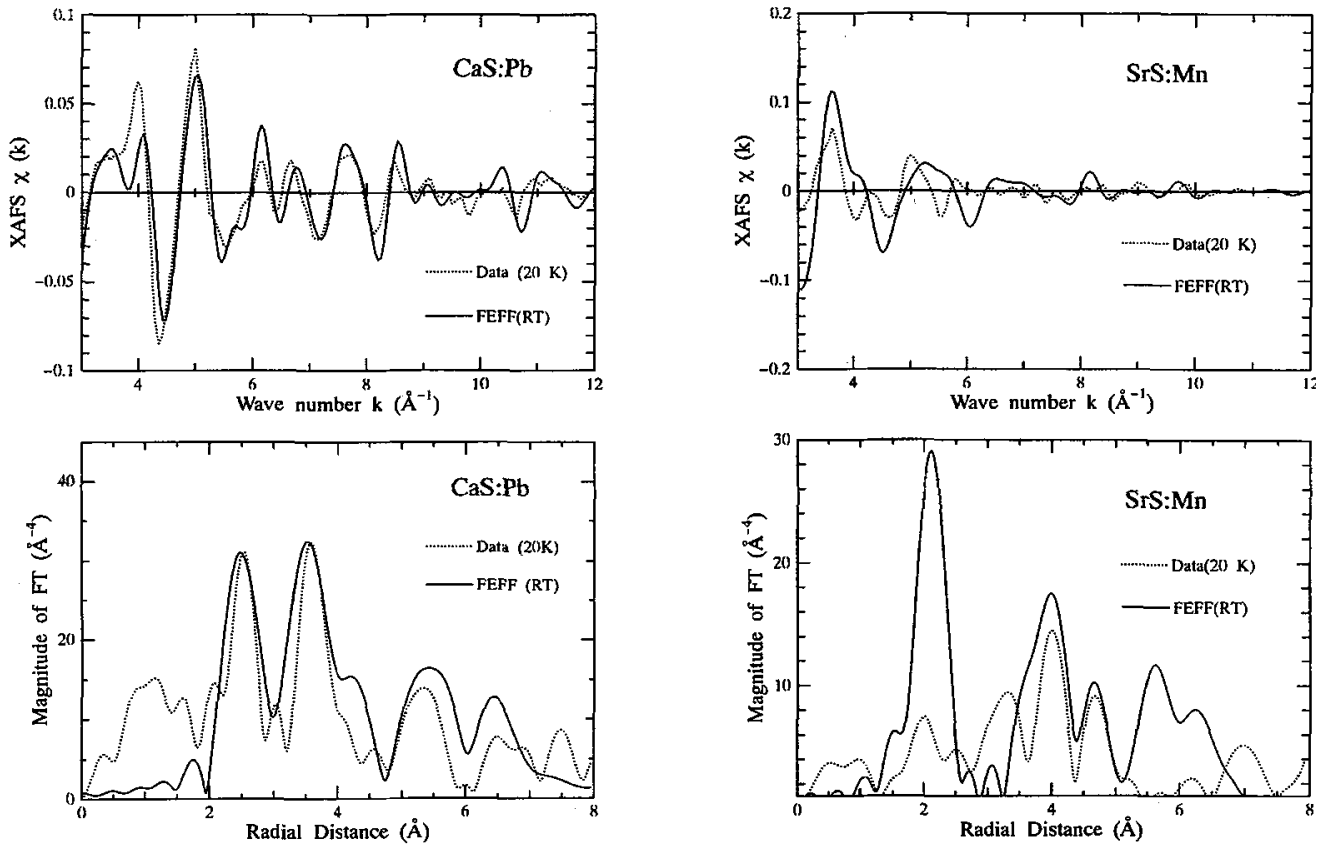

Figure 14: Comparison of the experimental and calculated spectra $\chi(k)$ 's and their Fourier transforms of $\mathbf{k}^{3}$-weighted $\chi(\mathbf{k})$ in $\mathrm{CaS}: \mathrm{Pb}$.

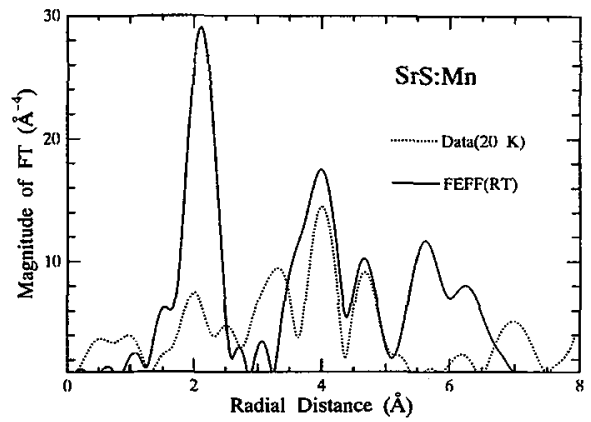

Figure 15: Comparison of the experimental and calculated spectra $\chi(k)$ 's and their Fourier transforms of $k^{3}$-weighted $\chi(k)$ in $\mathrm{SrS}: \mathrm{Mn}$. 


\section{Acknowledgments}

The works reported in this paper have been performed with the collaboration of Drs. H. Maeda and N. Yamashita of Okayama University, Dr. S. Emura of ISIR, Osaka University, and Dr. M. Nomura in the Photon Factory. The author is indebted to Dr. K. R. Bauchspiess for the analysis program. The experiments have been supported from the Photon Factory partly through Proposal No. 91-032.

\section{References}

[1] Fowler W. B., Physics of Color Centers (Academic Press, New York, 1968).

[2] Ref. [1], Chap. 2

[3] Song K. S., Williams R. T., Self-Trapped Excitons 2nd edition (Springer, 1996).

[4] Mikkelsen Jr. J. B., Boyce J. C., Phys. Rev. B 28 (1983) 7130-7140.

[5] Mikkelsen Jr. J. B., Boyce J. C., EXAFS and Near Edge Structure II, K. O. Hodgson, B. Hedman, and J. E. Penner-Hahn Eds. (Springer-Verlag, Berlin, Heidelberg, New York, Tokyo, 1984) pp. 426.431.

[6] Yokoyama T., Takamutsu F., Seki K., Miyake K., Tani T., Ohta T., Jpn. J. Appl. Phys. 29 (1990) L1486-L1489.

[7] Sato H. Yokoyama T., Ono I., Kaneyuki K., Ohta T., Jpn. J. Appl. Phys. 31 (1992) 1118-1123.

[8] Mayanovic R. A., Pong W. -F., Bunker B. A., Phys. Rev. B 42 (1990) 11174-11182.

[9] Murata T., EXAFS and Near Edge Structure III, K. O. Hodgson, B. Hedman, and J. E. Penner-Hahn Eds. (Springer-Verlag, Berlin, Heidelberg, New York, Tokyo, 1984) pp. 432-434.

[10] Nomura M., Koyama A., X-ray Absorption Fine Structure, S. Samar Hasnain Ed. (Ellis and Horwood, London, 1991) pp. 666-669.

[11] Lytle F. W., Greegor R. B., Sandstrom D. R., Marques E. C., Wong J., Spiro C. L., Huffman G. P., Huggins F. E., Nucl. Instum. Methods 226 (1984) 542-548.

[12] Eanes E. D., Costa J. L., MacKnezie A., Warburton W, Rev. Sci. Instum. 51 (1980) 1579-1581.

[13] Cook J. W., Sayers D. E., J. Appl. Phys. 52 (1981) 5024-5031.

[14] Lytle F. W., Sayers D. E., Stern E. A., Reports on the International Workshops on Standards and Criteria in XAFS. Xray Absorption Fine Structure, S. Samar Hasnain Ed. (Ellis and Horwood, London, 1991) pp. 751-770.

[15] Bauchspiess K. R., Jpn. J. Appl. Phys. 32 (1993) Suppl. 32-2 131-133.

[16] Rehr J. J., Albers R. C., Zabinsky S. I., Phys. Rev. Lett. 69 (1992) 3397-3400.

[17] Malzfeldt W., Niemann W., Rabe P., Schwentner N., EXAFS and Near Edge Structure, A. Bianconi, L. Incoccia, S. Stipcich Eds. (Springer-Verlag, Berlin, Heidelberg, New York, Tokyo, 1983) pp. 203-205.

[18] Cardona M., Solid State Physics Suppl. 11, F. Seitz, D. Turnbull, and H. Ehrenreich Eds. (Academic Press, New York and London, 1969).

[19] Petitpierre O., Stern E. A., EXAFS and Near Edge Structure III, K. O. Hodgson, B. Hedman, and J. E. Penner-Hahn Eds. (Springer-Verlag, Berlin, Heidelberg, New York, Tokyo, 1984) pp. 509-510.

[20] Emura S., Maeda H., Physica B 208 \& 209 (1995) 235-236. 